\title{
Kainic Acid-Induced Golgi Complex Fragmentation/Dispersal Shifts the Proteolysis of Reelin in Primary Rat Neuronal Cells: An In Vitro Model of Early Stage Epilepsy
}

\author{
Yuji Kaneko • Robert Sullivan • Travis Dailey • \\ Fernando L. Vale • Naoki Tajiri • Cesar V. Borlongan
}

Received: 16 December 2014 / Accepted: 22 February 2015 / Published online: 21 March 2015

(C) The Author(s) 2015. This article is published with open access at Springerlink.com

\begin{abstract}
The endoplasmic reticulum-lysosome-Golgi network plays an important role in Reelin glycosylation and its proteolytic processing. Golgi complex fragmentation is associated with the separation of Reelin from this network. Kainic acid (KA) is an excitotoxic agent commonly used to induce epilepsy in rodents. The relationship between KA-induced neuronal damage and Golgi complex fragmentation has not been investigated, leaving a major gap in our understanding of the molecular mechanism underlying the development of pathophysiology in epilepsy. We cultured primary rat cortical neurons eitherin ambient condition (control) or treated with a range of KA doses to reveal whether Golgi complex fragmentation impaired neuronal function. The half-life maximal inhibitory concentration $\left(I C_{50}\right)$ value of $\mathrm{KA}$ was detected to be approximately $5 \mu \mathrm{M}$, whereby at these concentrations, KA impaired neuronal viability, which was closely associated with initial Golgi complex fragmentation and subsequent reduction in both the expression and glycosylation patterns of Reelin. These findings implicate that Golgi complex fragmentation and Reelin dysfunction are key contributors to neuronal cell death in the early stage of epilepsy pathophysiology, thereby representing as novel disease biomarkers, as well as potent therapeutic targets for epilepsy.
\end{abstract}

Keywords Initiating epilepsy $\cdot$ Kainic acid · Glycosylation · Primary rat neuronal cell $\cdot$ Golgi protein

Y. Kaneko $(\bowtie) \cdot$ R. Sullivan $\cdot$ T. Dailey $\cdot$ F. L. Vale $\cdot$ N. Tajiri $•$

C. V. Borlongan $(\bowtie)$

Center of Excellence for Aging and Brain, Department of

Neurosurgery and Brain Repair, University of South Florida College

of Medicine, 12901 Bruce B Downs Blvd, Tampa, FL 33612, USA

e-mail: ykaneko@health.usf.edu

e-mail: cborlong@health.usf.edu

\section{Introduction}

Epilepsy is a debilitating neurological disorder affecting approximately $2 \%$ of the world's population. Over three million Americans suffer from some form of epilepsy, with mesial temporal lobe epilepsy (TLE) being the most common, arising from the temporal lobe structures of amygdala, hippocampus, and parahippocampal gyrus [1]. Despite the availability of many antiepileptic drugs (AEDs), greater than $30 \%$ of TLE patients will have seizures refractory to standard therapeutics, highlighting the need for more effective therapies. [2].

The Golgi complex is localized around the centriole, a regulator of cell-cycle progression, and is a cytoplasmic organelle that participates in maturation and modification of membrane proteins during transport from the site of synthesis in the endoplasmic reticulum (ER) [3, 4]. Golgi complex fragmentation irreversibly occurs during apoptosis, when the Golgi complex fragments to produce clusters of vesicles that disperse throughout the cytoplasm [5]. The Golgi complex fragmentation not only is essential for cell entry into mitosis [6] but also is a pathological feature of several neurodegenerative diseases including Alzheimer's disease [7], Parkinson's disease [8], amyotrophic lateral sclerosis [9], and CreutzfeldtJakob disease [10].

Reelin is an extracellular matrix glycoprotein [11] synthesized and secreted by Cajal-Retzius cells in the marginal zone of the cortex [12]. It localizes to Golgi complex [13] where it is extensively processed within the ER-lysosome-Golgi network [5]. Secreted Reelin binds the apolipoprotein 2 receptor (ApoE2R) and the very low density lipoprotein receptor (VLDLR) [14] as well as the extracellular domain of ephrin B proteins (EFNBs) [15], which associate with ApoE2R and VLDLR. These interactions in turn induce phosphorylation of the cytoplasmic adaptor protein Disabled-1 (Dab-1) by Src 
family tyrosine kinases (SFKs), Fyn and Src, associated with signaling of integrin pathways [16]. The physiological dysfunction of Reelin has been implicated in the pathogenesis of several neurodegenerative diseases including epilepsy[17, 18], depression [19], schizophrenia [15], and Alzheimer's disease $[11,20]$. The ER-lysosome-Golgi network assumes a major function in Reelin protein modification (glycosylation), its proteolytic processing (180- and $320-\mathrm{kDa}$ fragments), and the synthesis of proteoglycans, which are composed of molecules of extracellular matrix [11].

Unilateral injection of kainic acid (KA), an agonist to the excitatory neurotransmitter glutamate, into rodent brain induces epileptic activity and epileptic seizures, and granule cell dispersion [21]. KA possesses neurotoxicity involving epileptogenic effect via the $\alpha$-amino-3-hydroxy-5-methyl-4isoxazolepropionic acid (AMPA) and kainate receptors that respond to the neurotransmitter glutamate [22]. KA-induced caspase activation and subsequent DNA fragmentation are key features of the apoptotic pathway leading to neuronal death [23, 24]. However, KA-induced Golgi complex fragmentation remains to be examined in electrophysiological hyperactivity models, which mimic seizure and epilepsy.

In this study, we observed that the administration of KA in primary rat neuronal cells promoted neuronal dysfunction by facilitating the Golgi complex fragmentation/dispersal, which in turn may damage a sophisticated network of biochemical reactions involved in energy production and macromolecular biosynthesis. The present results demonstrated that a dysfunctional Golgi-Reelin interaction may contribute to the disease pathophysiology of epilepsy.

\section{Materials and Methods}

\section{Cell Culture}

Primary rat neuronal cells (PRNCs) were obtained from BrainBit (E18 rat cortex). According to the previous reference[25], cells $\left(4 \times 10^{4}\right.$ cells/well $)$ were suspended in $200 \mu \mathrm{l}$ Neural Medium (NbActive 4, BrainBit NB4-500) containing $2 \mathrm{mML}$-glutamine and $2 \%$ B27 in the absence of antibiotics and grown in poly-L-lysine-coated 96-well plates (BD 354516) at $37{ }^{\circ} \mathrm{C}$ in humidified atmosphere containing $5 \% \mathrm{CO}_{2}$ in $40 \%$ of the neuron and $60 \%$ astrocyte cell population [25]. After 3 days of culturing (approximately $60 \%$ cell confluence), PRNCs were exposed to KA (1.25 $\mathrm{nM} \sim 125 \mu \mathrm{M})$ for 3 days at $37^{\circ} \mathrm{C}$.

\section{Measurement of Cell Viability}

Measurement of cell viability was performed by both fluorescent live/dead cell assay and trypan blue exclusion method [26]. A two-color fluorescence cell viability assay was performed by calcein acetoxymethyl ester (calcein-AM, Invitrogen C3099) to be retained within live cells, including an intense uniform green fluorescence and ethidium homodimer (EthD-1) to bind the nuclei of damaged cells. Following treatment, the cells were incubated with $2 \mu \mathrm{M}$ calcein-AM and $4 \mu \mathrm{M}$ EthD-1 for $45 \mathrm{~min}$ at room temperature in the dark. After washing once with phosphate-buffered saline (PBS) (Sigma-Aldrich P-3813), the green fluorescence of the live cells was measured by the Gemini EX florescence plate reader (Molecular Device), excitation at $490 \mathrm{~nm}$ and emission at $520 \mathrm{~nm}$. In addition, trypan blue (Gibco 15250, 0.4 \%) exclusion method was conducted, and mean viable cell counts were calculated in four randomly selected areas $\left(1 \mathrm{~mm}^{2}, n=10\right)$ to reveal the cell viability. Briefly, within $5 \mathrm{~min}$ after adding trypan blue, we digitally captured under microscope $(\times 200)$ ten pictures (approximately 100 cells/picture) for each condition, then randomly selected five pictures, and counted the number of cells for each individual treatment condition. Normalized cell viability was calculated from the following equation: viable cells $(\%)=[1.00-($ number of blue cells $/$ number of total cells) $] \times 100$. To precisely calibrate the cell viability, the values were standardized from florescence intensity and trypan blue data [25].

\section{Measurement of Mitochondrial Activity}

Following cell culture, reduction of 3-(4,5-dimethyl-2thiazoyl)-2,5-diphenyltetrazolium bromide (MTT) (Roche 11465007001) by mitochondrial dehydrogenases was used as a measure of mitochondrial activity as previously described [25]. Briefly, the cells were treated with $0.5 \mathrm{mg} / \mathrm{ml} \mathrm{MTT} \mathrm{so-}$ lution at $37^{\circ} \mathrm{C}$ for $4 \mathrm{~h}$ and subsequently incubated with lysis buffer for $14 \mathrm{~h}$ in the incubator in a humidified atmosphere at $37{ }^{\circ} \mathrm{C}$ and $5 \% \mathrm{CO}_{2}$. The optical density of solubilized purple forzmazan was measured at $570 \mathrm{~nm}$ on a Synergy HT plate reader (Bio-Tex).

\section{Western Blot Analysis}

PRNCs were treated with CelLytic MT mammalian lysis reagent (Sigma-Aldrich, C3228) with protease inhibitor cocktail (Sigma-Aldrich, I3786). The lysate was centrifuged at $3000 \mathrm{~g}$ and $4{ }^{\circ} \mathrm{C}$ for $15 \mathrm{~min}$, and the supernatant was stored at $-80{ }^{\circ} \mathrm{C}$ until used. Protein samples $(10 \sim 60 \mu \mathrm{g} /$ lane) were run on $4 \sim 14 \%$ Tris-Glycine SDS-PAGE gel [27] and then transferred onto a nitrocellulose membrane (Bio-Rad 162-0112) at $30 \mathrm{~V}, 4{ }^{\circ} \mathrm{C}$ for $14 \mathrm{~h}$. The nitrocellulose membranes were treated with PBS containing $0.1 \%$ Tween-20 and $5 \%$ non-fat milk (Bio-Rad 170-6404) for $45 \mathrm{~min}$ at room temperature. Membranes were then incubated with the primary antibodies, anti-Reelin mouse antibody (LSBio LS-C90872/49638, 1/500), anti-human natural killer-1 (HNK1) rabbit antibody (Bioss bs-1635R, 1/500), 
anti-glyceraldehyde-3-phosphate-dehydrogenase (GAPDH) [6C5] mouse antibody (Abcam 8245, 1/5,000), and rabbit polyclonal anti-cis-Golgi glycoprotein of $130 \mathrm{kDa}$ (GM130, Abcam ab28049, 1/500), at $4{ }^{\circ} \mathrm{C}$ for $14 \mathrm{~h}$. After washing with PBS containing $0.1 \%$ Tween-20 (PBST), the nitrocellulose membrane was incubated with donkey antimouse IRDye $800^{\circledR} \mathrm{CW}$ secondary antibody (LI-COR 926$32212,1 / 5000)$ or donkey anti-rabbit IRDye $800^{\circledR} \mathrm{CW}$ secondary antibody (LI-COR 926-32213, 1/5000) for $90 \mathrm{~min}$ at room temperature in the dark. Immunoreactive detection using near-infrared fluorescence was performed according to protocol of Odyssey ${ }^{\circledR}$ Infrared Imaging System (LI$\left.\mathrm{COR}^{\circledR}\right)$. Molecular weight estimation of the full-length Reelin protein $(400 \mathrm{kDa})$ and its fragments (180 and $320 \mathrm{kDa})$ using SeeBlue ${ }^{\circledR}$ Plus Pre-stained standard (Invitrogen, LC5925) was calculated from plotting a standard curve of logarithm molecular weight versus target protein mobility.

\section{IP Assays}

After PRNC, whole cell lysate ( $400 \mu \mathrm{g} / 100 \mu$ l PBS containing protease inhibitors (Sigma-Aldrich, I3786)) was interacted with anti-Reelin mouse monoclonal antibody (LSBio LSC90872/49638, 1/50) at $4{ }^{\circ} \mathrm{C}$ for $16 \mathrm{~h}$, and the lysate was incubated with $50-\mu$ l Protein $\mathrm{G}$ agarose beads (Invitrogen 10-1241) at $4{ }^{\circ} \mathrm{C}$ for $4 \mathrm{~h}$ [11]. Following antibody-protein, $\mathrm{G}$ complexes were washed three times with $4{ }^{\circ} \mathrm{C}$ RIPA buffer (Sigma-Aldrich R0278), and immune complexes were recovered by heating the samples at $95{ }^{\circ} \mathrm{C}$ for $5 \mathrm{~min}$ in Laemmli SDS lysis buffer (Bioland Scientific LLC SAB02-01).

\section{Immunocytochemistry Analysis}

After PRNCs $\left(8 \times 10^{4}\right.$ cell/well $)$ were cultured in $400-\mu 1$ Neural medium containing $2 \mathrm{mML}$-glutamine and $2 \%$ B27 in the absence of antibiotics in poly-L-lysine 8-chamber (BD 354632) for 3 days, the cells were then exposed to $5 \mu \mathrm{M}$ KA for 3 days and fixed in $4 \%$ paraformaldehyde [25]. The cells were washed five times for $10 \mathrm{~min}$ in PBST. Then, they were blocked by $5 \%$ normal goat serum (Invitrogen 50062Z) in PBST for $1 \mathrm{~h}$ at room temperature. Primary antibodies, mouse monoclonal anti-Golgi formiminotransferase cyclodeaminase (FTCD, Abcam ab27043, 1/400), rabbit polyclonal anti-cis-Golgi glycoprotein of $130 \mathrm{kDa}$ (GM130, Abcam ab28049, 1/400), rabbit polyclonal anti-ERp29 (Abcam ab11420, 1/500) for detecting the ER marker protein, rabbit polyclonal anti-LAMP (Abcam ab24170, 1/100) for detecting the lysosome marker protein, and mouse monoclonal anti-Reelin (Abcam ab78540, 1/400) were used. The cells were incubated overnight at $4{ }^{\circ} \mathrm{C}$ with primary antibody with $5 \%$ normal goat serum. The cells were washed five times for $10 \mathrm{~min}$ in PBST and then soaked in $5 \%$ normal goat serum in
PBST containing corresponding secondary antibodies, goat anti-mouse IgG-Alexa 488 (green, Invitrogen A11029, 1/1, 000) and goat anti-rabbit IgG-Alexa 594 (red, Invitrogen A11037, 1/1,000) for 90 min in the dark. Finally, cells were washed five times for $10 \mathrm{~min}$ in PBST and three times for 5 min in PBS, then processed for Hoechst 33258 (Sigma B2883) for $30 \mathrm{~min}$, washed in PBS, and cover-slipped with Fluoromount. Immunofluorescent images were visualized using confocal microscope (Olympus FV1000). Control experiments were performed with the omission of the primary antibodies yielding negative results.

\section{Data Analysis}

Data were evaluated using one-way analysis of variance (ANOVA) followed by post hoc Bonferroni's $t$ tests. Statistical significance was preset at $p<0.05$. Data are represented as means \pm SD from quintuplicates of each treatment condition. The value of $I C_{50}$ was calculated from the equation $Y=A+[(B$ $\left.-A) /\left(1+\left(x / I C_{50}\right)^{h}\right)+(B-A) /(F-A)-1\right]$, where $Y$ is the observed value of individual KA concentration $(x), A$ is the $y$ axis value of the bottom plateau, $B$ is maximal value, $x$ is the concentration of KA, $h$ is the Hill coefficient $(h \approx 1), F=(B+$ Baseline) $/ 2$, and Baseline is the $y$-axis value that defines $0 \%$, maximal inhibition by KA [28]. The $I C_{50}$ values were estimated by plotting the logarithmic values of the different KA doses using GraphPad Prism $6^{\circledR}$ software.

\section{Results}

Treatment of PRNCs with KA Resembles the Early Stage of Epilepsy

PRNC viability and mitochondrial activity were significantly decreased in a dose-dependent manner with KA administration; the estimated $I C_{50}$ values for cell viability and mitochondrial activity are $5.89 \pm 0.185 \mu \mathrm{M}$ and $2.79 \pm 0.515 \mu \mathrm{M}$, respectively (Fig. 1). Topiramate [2,3:4,5-bis- $O$-(1methylethylidene)- $b$-D-fructopyranosesulfamate] (TPM, Sigma-Aldrich T0575), a commonly used AED [21, 22], antagonizes the AMPA/kainate receptor-mediated signaling pathway in cultured neurons in which the drug was shown to produce a slow depression of KA inward current activation [29]. To confirm that reduction of both cell viability and the mitochondrial activity depends on the KA-induced activation of AMPA/kainate receptors, cell viability and the mitochondrial activity were compared in the presence of both KA and TPM with that of KA alone. After exposure to $5 \mu \mathrm{M} \mathrm{KA}$, both cell viability $\left(F_{2,26}=73.37, p<0.0001\right)$ (Fig. 2a) and mitochondrial activity $\left(F_{2,23}=43.87\right.$, $p<0.0001$ ) (Fig. 2b) were significantly decreased. Treatment of PRNCs with TPM increased both cell viability and 


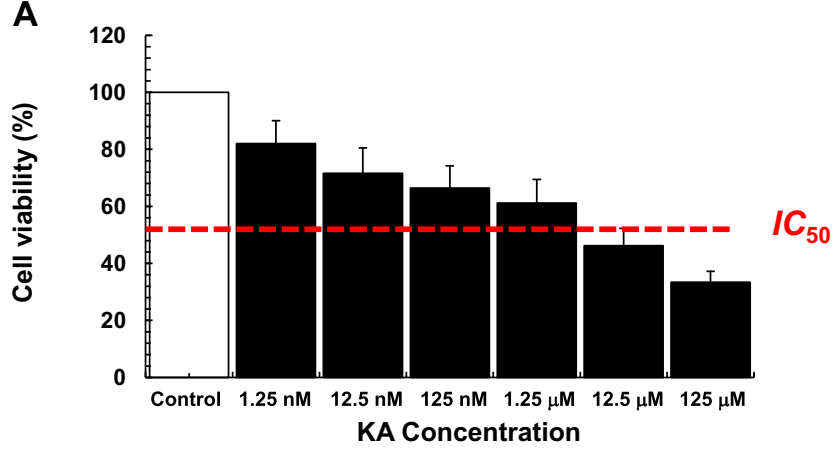

B

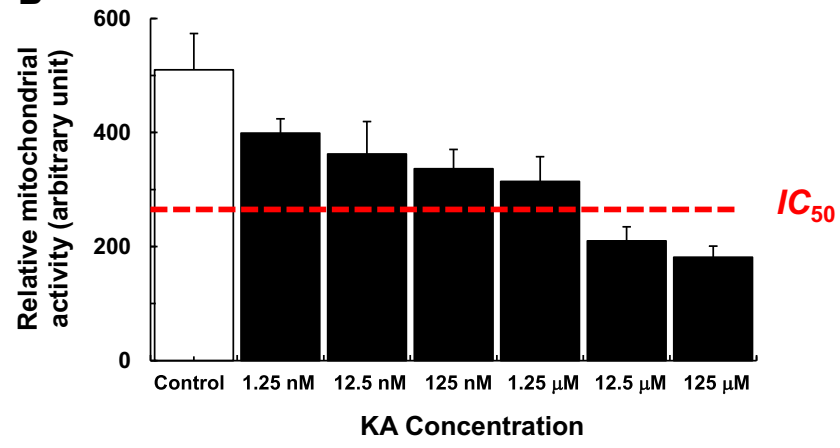

Fig. 1 Dose-response effects on cell viability and relative mitochondrial activity based on KA concentrations. After cultured PRNCs were incubated with $\mathrm{KA}$ for 3 days at $37^{\circ} \mathrm{C}$, cell viability and mitochondrial activity were measured by using calcein assay (a) and MTT assay (b), respectively. The $I C_{50}$ values were estimated by using GraphPad Prism $6^{\circledR}$ software

mitochondrial activity in PRNCs exposed to KA $(p<0.05)$. Altogether, these results indicate that this in vitro KA paradigm is reminiscent of early stage epilepsy.

\section{KA Induces the Collapse of ER-Lysosome-Golgi Network}

FTCD co-localizes with GM130 on the Golgi complex membrane [30]; therefore, these antibodies were used in combination to assess Golgi complex structure. Following incubation of PRNCs in $5 \mu \mathrm{M}$ KA (previously calculated $I C_{50}$ of cell viability) for 3 days at $37{ }^{\circ} \mathrm{C}$, Golgi complex fragmentation/ dispersal (Fig. 3) and collapse of ER-lysosome-Golgi network were observed (Figs. 4 and 5). This study is the first to report that the Golgi complex fragmentation occurs in the early stages of epilepsy in vitro. The Golgi complex not only serves a pivotal role in trafficking of ion channels, plasma receptors, and other transmitter molecules but also mediates transport of exogenous molecules by retrograde and trans-synaptic signal transduction [4]. Appropriate Golgi complex localization/ positioning is essential for the processing, sorting, and transport of proteins and lipids involved in cell wound healing and maintenance of the membrane potential [3]. We hypothesized that Golgi complex fragmentation/dispersal influences the processing of extracellular matrix molecule Reelin.

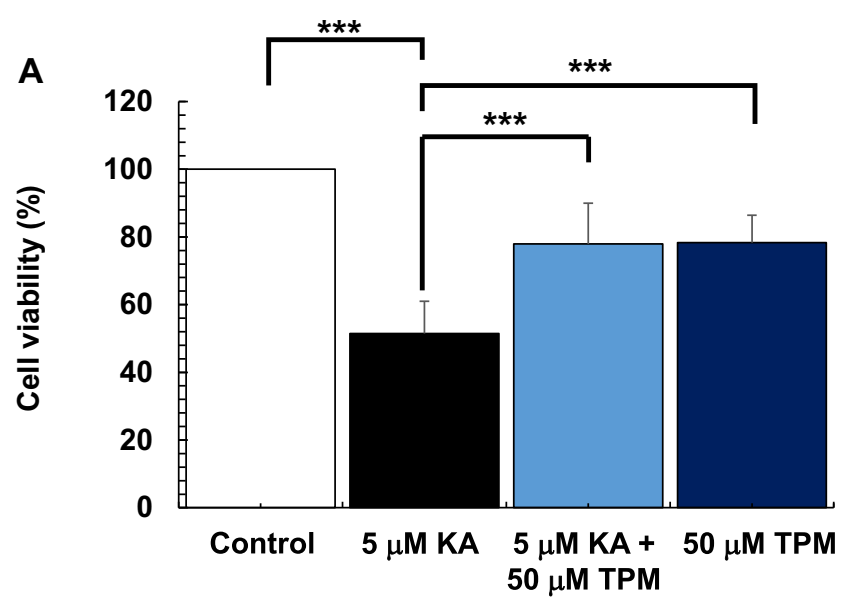

B

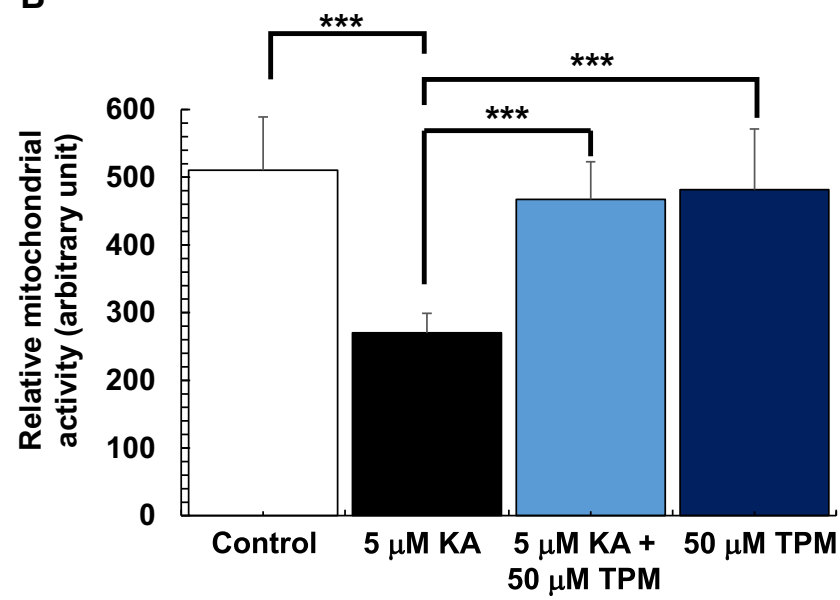

Fig. 2 Topiramate (TPM) significantly reduced both cell death and mitochondrial dysfunction induced by KA administration. Cultured PRNCs were subjected to $5 \mu \mathrm{M} \mathrm{KA}$ alone, or $5 \mu \mathrm{M} \mathrm{KA}$ in the presence of $50 \mu \mathrm{M}$ TPM, or $50 \mu \mathrm{M}$ TPM alone for 3 days at $37{ }^{\circ} \mathrm{C}$, then cell viability and mitochondrial activity were measured by using calcein assay (a) and MTT assay (b). There were no significant differences in both cell viability and mitochondrial activity between control and $50 \mu \mathrm{M}$ TPM only treatment. ${ }^{* * *} P<0.001$

Golgi Complex Fragmentation/Dispersal Influences Reelin Processing

Reelin is an extracellular matrix glycoprotein that has important functions in brain development, adult neurogenesis, and maintenance of synaptic plasticity [12]. Reelin is tightly regulated at ER-lysosome-Golgi network and modified at Golgi complex [13]. Matrix metalloproteinases cleave the fulllength Reelin protein $(400 \mathrm{kDa})$ into both 180 - and $320-\mathrm{kDa}$ fragments [31]. The $320-\mathrm{kDa}$ fragment is required for proper protein folding and essential of signaling pathways' activity via the specific Reelin receptors. We found that following KAinduced Golgi complex fragmentation, intracellular Reelin was dispersed from the Golgi complex (Fig. 6, represented by arrow heads and Fig. 7). Of note, there are three types of intracellular Reelin $(180,320$, and $400 \mathrm{kDa})$, which 

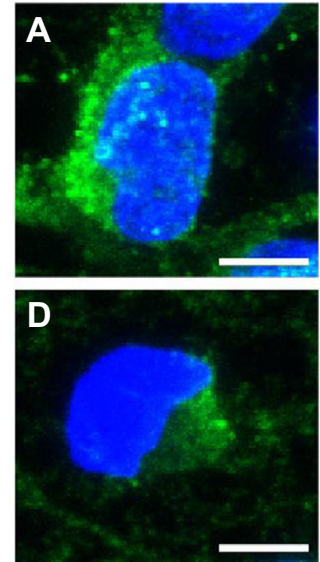

Golgi (FTCD) + Nuclei
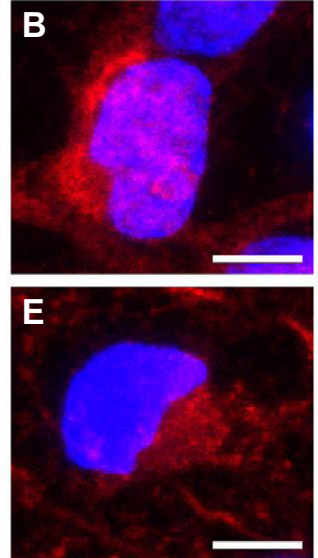

Golgi (GM130) + Nuclei
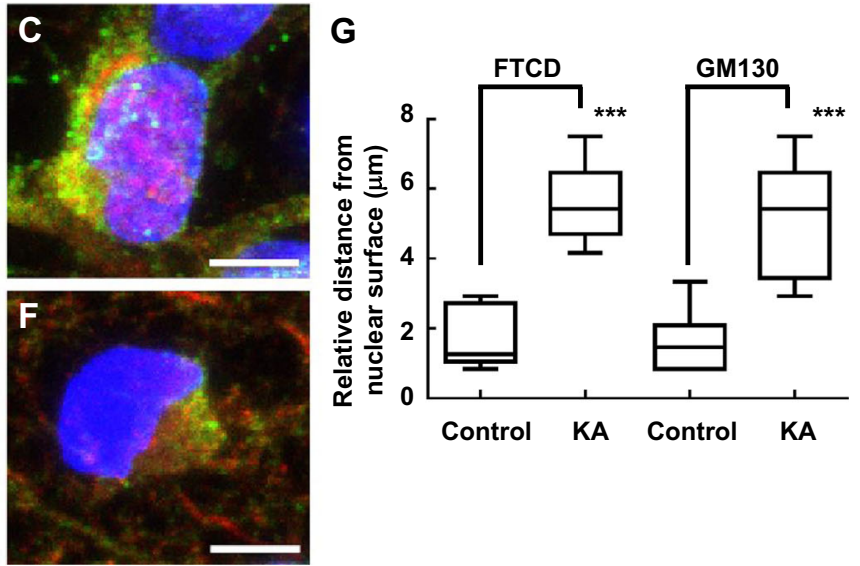

Merge

Fig. 3 Immunofluorescence showing gross changes in Golgi complex distribution/morphology in response to KA administration with PRNCs for 3 days at $37^{\circ} \mathrm{C}$. PRNCs were fixed and stained for the Golgi complex using antibodies against FTCD (green) and GM130 (red) and for nuclei using Hoechst 33258 (blue). a-c Control, FTCD, and GM130 work in tandem with localizing closely nuclei, whereas d-f PRNCs were

unfortunately could not be distinguished intracellularly via immunocytochemistry when examining these Reelin subtypes and glycosylation. Thus, for immunocytochemistry, while the relative distances from nuclear surface of FTCD, GM130, Erp29, and LAMP were significantly longer in KA than controls (Figs. 3-5), Reelin was detected not to significantly differ from the controls (Fig. 6). On the other hand, protein expression (as shown in subsequent Western blot analysis) clearly showed the changes in ratio of intracellular Reelin subtypes and their glycosylation patterns. Accordingly, Western blot analysis (Fig. 8a, b) revealed that the 320-kDa fragment, representing the secreted form of Reelin[32], was significantly incubated with $5 \mu \mathrm{M} \mathrm{KA}$ for 3 days at $37{ }^{\circ} \mathrm{C}$. g Quantifications correspond to Golgi fragmentation, distance of reconstructed antiFTCD, and anti-GM130 fluorescent signal from nuclear surface. In control condition, $P$ value of FTCD versus GM130 is 0.687 , and the value in KA condition is 0.369 . KA-induced epilepsy provoked Golgi complex fragmentation/dispersal. $* * * P<0.001$. Scale bars $=5 \mu \mathrm{m}$

decreased in KA-treated PRNCs compared to control, whereas the full-length Reelin protein $(400 \mathrm{kDa})$ in KA-treated PRNCs was significantly increased $(p<0.05)$, indicating that proteolytic processing of Reelin was decreased in this acute KA neurotoxicity paradigm that mimics the early stage of epilepsy. Furthermore, the mobility of the top two bands in control was slightly shorter than that of PRNCs treated with $5 \mu \mathrm{M}$ KA for 3 days at $37^{\circ} \mathrm{C}$, demonstrating that these Reelin fragments are more extensively processed under normal physiologic conditions when compared with the KA-induced neurotoxicity in vitro. Accordingly, this KA-induced epilepsy likely contributed to the initiation of Golgi complex
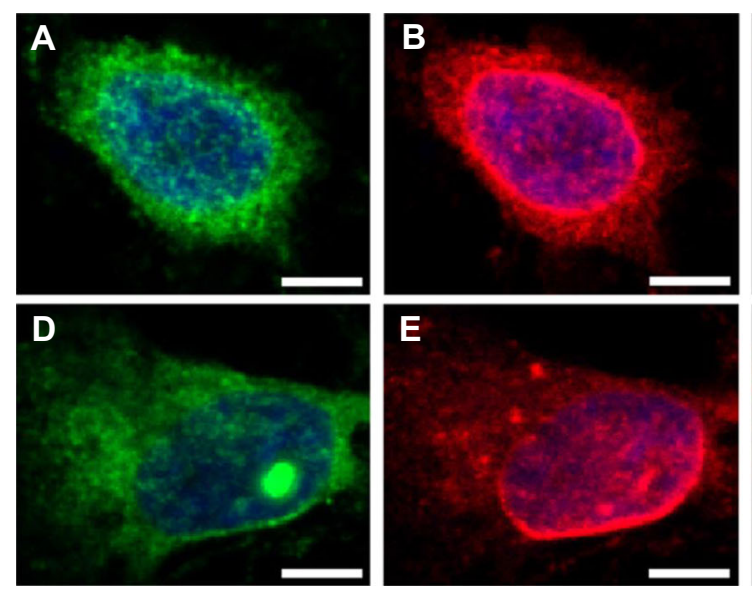

Golgi (FTCD) + Nuclei

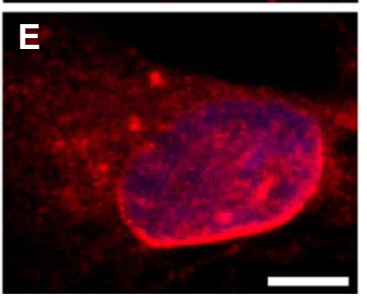

ERp29 + Nuclei

Fig. 4 Immunofluorescence showing gross changes interaction between Golgi complex and ER distribution/morphology in response to KA administration with PRNCs for 3 days at $37^{\circ} \mathrm{C}$. PRNCs were fixed and stained for the Golgi complex and ER using antibodies against FTCD (green) and ERp29 (red), respectively, and for nuclei using Hoechst 33258 (blue). a-c Control, Golgi closely localized with ER which
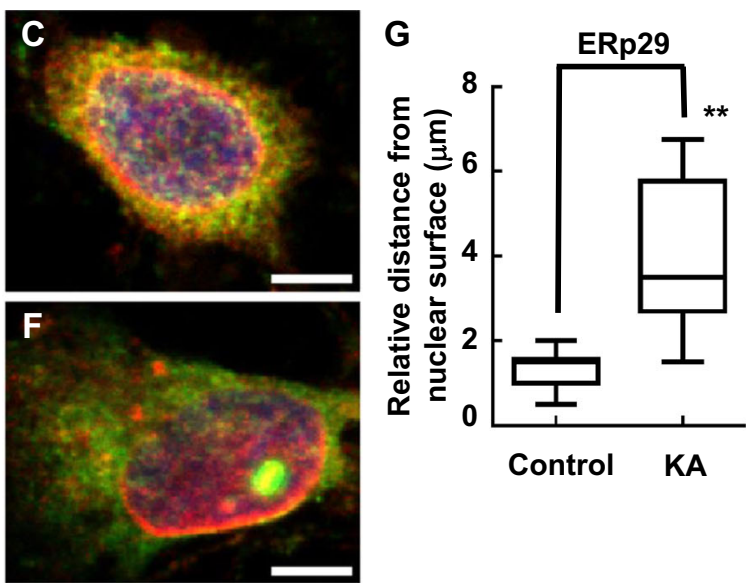

Merge

distributed around nuclei. d-f PRNCs were incubated with $5 \mu \mathrm{M} \mathrm{KA}$ for 3 days at $37{ }^{\circ} \mathrm{C}$. KA-induced epilepsy provoked Golgi complex fragmentation/dispersal, and ER are seen dislocated around nuclei. $\mathrm{g}$ Quantification of ER dislocation from nuclear surface corresponded to distance of reconstructed anti-ERp29 fluorescent signal from nuclear surface. $* * P<0.01$. Scale bars $=5 \mu \mathrm{m}$ 

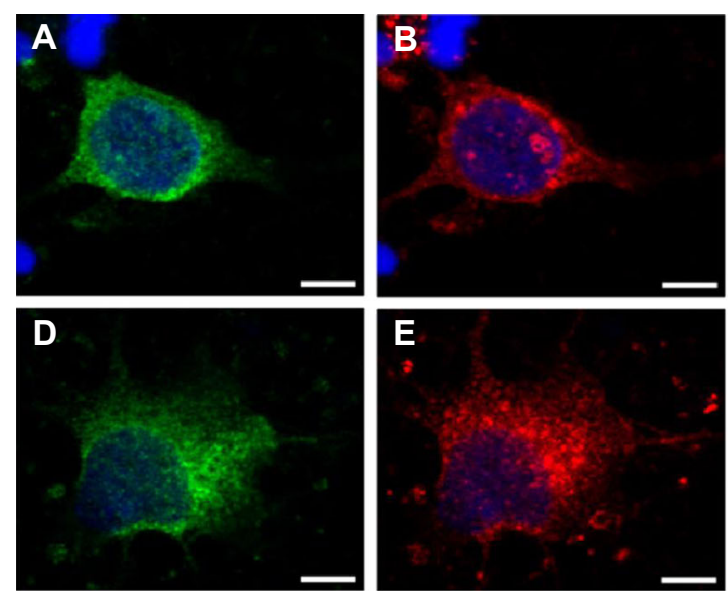

Golgi (FTCD) + Nuclei

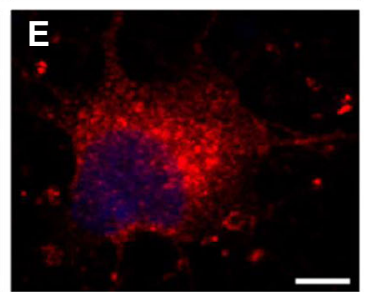

LAMP + Nuclei

Fig. 5 Immunofluorescence showing gross changes interaction between Golgi complex and lysosome distribution/morphology in response to KA administration with PRNCs for 3 days at $37^{\circ} \mathrm{C}$. PRNCs were fixed and stained for the Golgi complex and lysosome using antibodies against FTCD (green) and LAMP (red), respectively, and for nuclei using Hoechst 33258 (blue). a-c Control, Golgi, and lysosome are closely

fragmentation and the disruption of Reelin protein processing, subsequently resulting in dysfunctions such as decreased secreted Reelin, as well as impaired glycosylation.

HNK1 glycoepitope is expressed on the extracellular matrix of protein Reelin and is sequentially biosynthesized by glucuronyltransferase and/or sulfotransferase on the Golgi complex membrane [33]. To confirm whether Golgi complex fragmentation affects the glycosylation of Reelin, we performed Western blot analysis using the anti-HNK-1 antibody after Reelin fragments that were immunoprecipitated (described in "Materials and Methods"). We observed higher
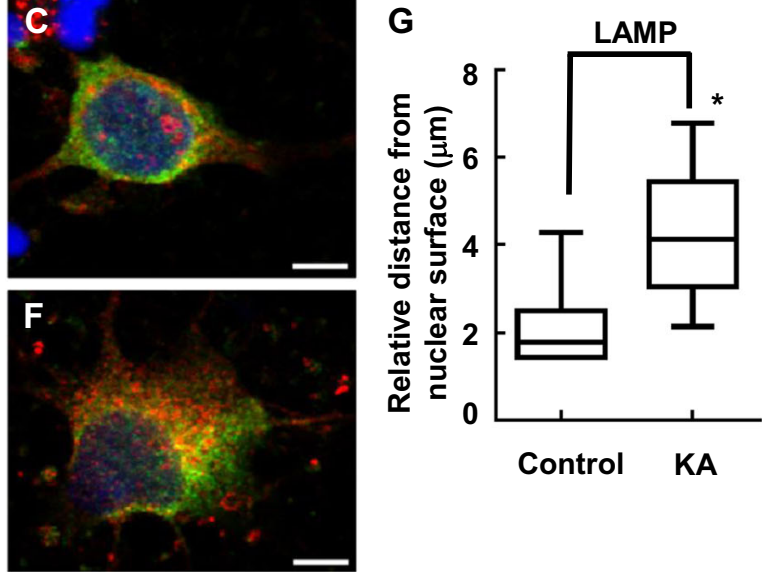

\section{Merge}

localized. d-f PRNCs were incubated with $5 \mu \mathrm{M}$ KA for 3 days at $37{ }^{\circ} \mathrm{C}$. KA-induced epilepsy provoked Golgi complex and lysosome dispersal. g Quantification of lysosome dispersal corresponded to distance of reconstructed anti-LAMP fluorescent signal from nuclear surface. ${ }^{*} P<0.05$. Scale bars $=5 \mu \mathrm{m}$

levels of glycosylated Reelin ( 320 and $400 \mathrm{kDa}$ ) in the control group when compared to our experimental group of PRNCs treated with $5 \mu \mathrm{M} \mathrm{KA}$ for 3 days (Fig. 8c, d), although the glycosylated 180-kDa Reelin fragment was similar between groups. These data demonstrated that Golgi complex fragmentation impairs not only proteolytic processing of Reelin but also its glycosylation in the Golgi apparatus (Fig. 8), resulting in a decrease of physiologically active Reelin in the early stages of epilepsy. Moreover, GM130 co-localizes with FTCD on the Golgi complex membrane and is a sensor of intracellular $\mathrm{pH}$ level. Here, we found that GM130 expression
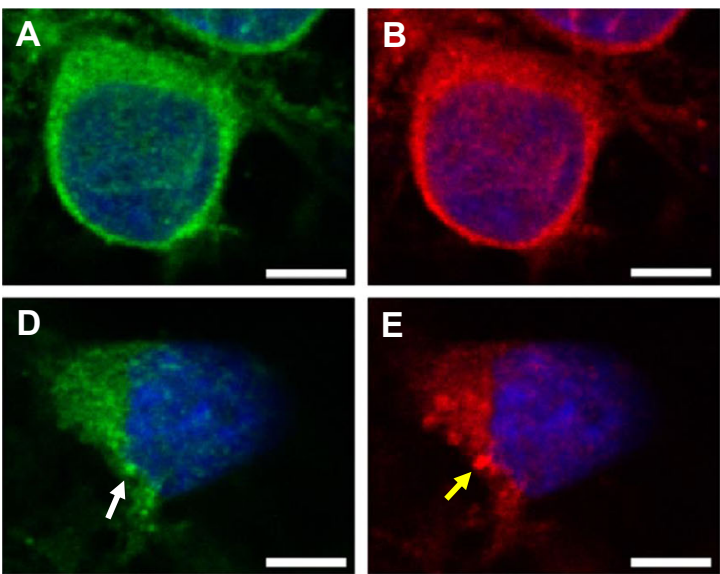

Reelin + Nuclei

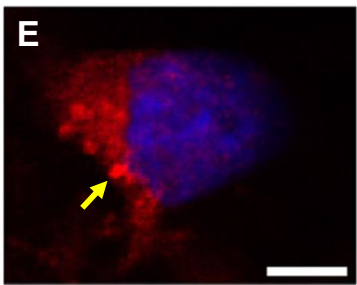

Golgi (GM130) + Nuclei
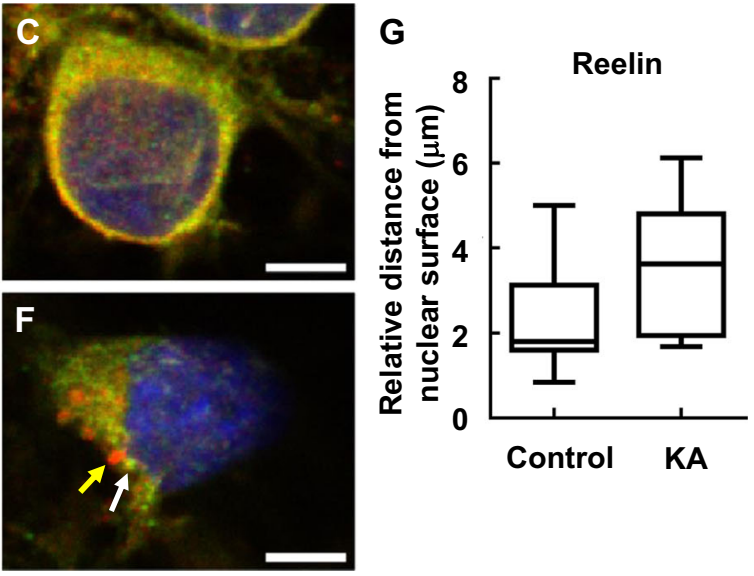

Fig. 6 Intracellular Reelin (white arrow) dislocated at Golgi complex (yellow arrow) in response to KA. PRNCs were cultured with KA for 3 days at $37{ }^{\circ} \mathrm{C}$. PRNCs were fixed and stained for Reelin and Golgi complex using antibodies against Reelin (green) and GM 130 (red), respectively, and for nuclei using Hoechst 33258 (blue). a-c Control,

Intracellular Reelin co-localized with Golgi complex, $\mathbf{d}-\mathbf{f}$ PRNCs were incubated with $5 \mu \mathrm{M} \mathrm{KA}$ for 3 days at $37^{\circ} \mathrm{C}$. g Quantification of Reelin distribution around nuclei corresponded to distance of reconstructed antiReelin fluorescent signal from nuclear surface. Scale bars $=5 \mu \mathrm{m}$ 


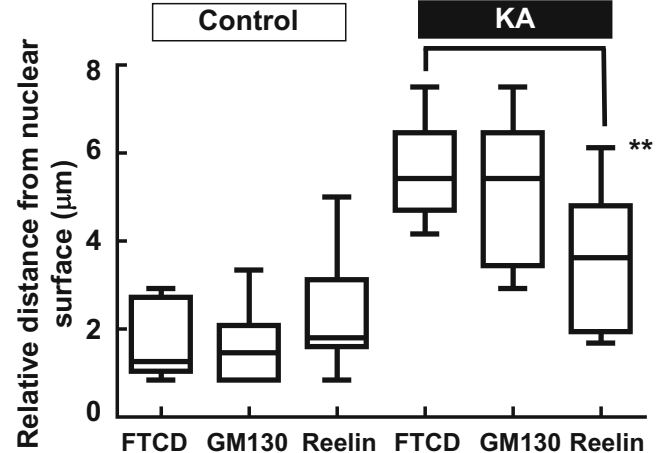

Fig. 7 Quantification of intracellular Reelin dislocated from Golgi complex. Comparison of distance from nuclear surface. The distribution of intracellular Reelin consists of Golgi complex in control condition, whereas in KA condition, the division of Reelin separated from distribution of Golgi complex. $* * P<0.01$

level under KA condition was significantly decreased (Fig. 9), suggesting PRNCs cytosol pH became acidic.

\section{Discussion}

Epilepsy may arise from multiple genetic mutations that produce functional deficits in a variety of voltage-dependent and/ or ligand receptor-mediated ion channels. For example, dysfunction of a voltage-dependent $\mathrm{Na}^{+}$channel in $\gamma$ aminobutyric acid (GABA) interneurons is critically
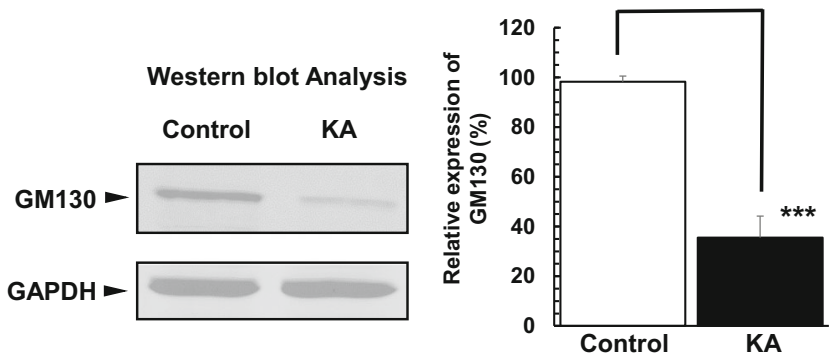

Fig. 9 Western blotting analysis of GM130 expression in PRNCs. Following incubation of PRNCs in $5 \mu \mathrm{M} \mathrm{KA}$ for 3 days at $37^{\circ} \mathrm{C}(\mathrm{KA})$ or in the absence of KA (control), GM130 expression level under KA condition was significantly decreased, indicating $\mathrm{pH}$ acidity of PRNC cytosol. $* * * P<0.001$

associated with the severe myoclonic epilepsy in infancy [34]. Despite the availability of several AEDs, which antagonize the activity of specific ions channels, greater than $30 \%$ of TLE patients will have seizures that are refractory to all standard therapeutics. The precise mechanisms that contribute to the initiation and propagation of seizure activity have not yet been clearly defined [22]; therefore, this study sought to examine the role by which Golgi complex fragmentation initiates epilepsy pathophysiology in a cell culture paradigm.

Progress in investigating epilepsy has been facilitated by the establishment of in vitro and in vivo epilepsy models [2]. Epilepsy treatment has rationally involved AEDs [22] and subsequently has been explored using surgical approaches including electrical stimulation [35]. TPM restricts excitatory
Fig. 8 Golgi complex fragmentation impairs Reelin mobilization. a, b Western blot analysis using anti-Reelin mouse antibody showed Reelin bands $(180,320$, and $400 \mathrm{kDa})$. In healthy neurons (control), bands of 320 and $400 \mathrm{kDa}$ Reelin mobilized shorter than that of epilepsy model (KA). c, d IP analysis using anti-Reelin mouse antibody demonstrated that the density of 320-kDa Reelin fragment and the full-length Reelin protein $(400 \mathrm{kDa})$ in healthy neuronal condition is significantly higher than that of epilepsy model, although 180$\mathrm{kDa}$ Reelin fragment is similarly expressed in both conditions. $* P<0.05$. **P $P<0.01$
A

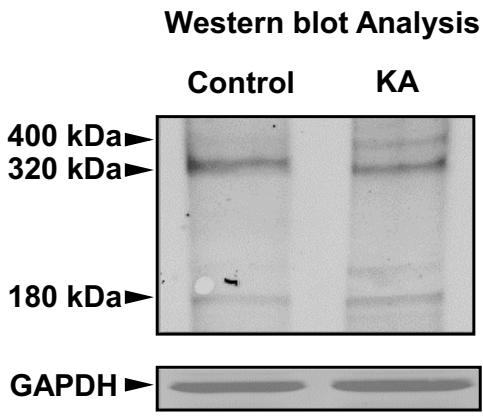

C

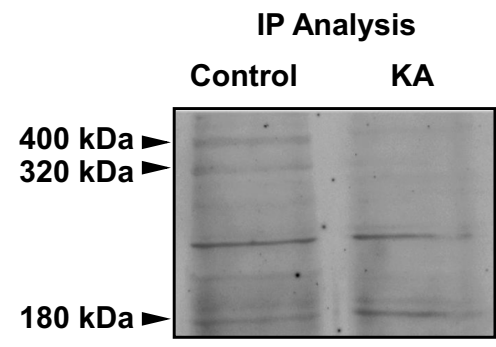

B

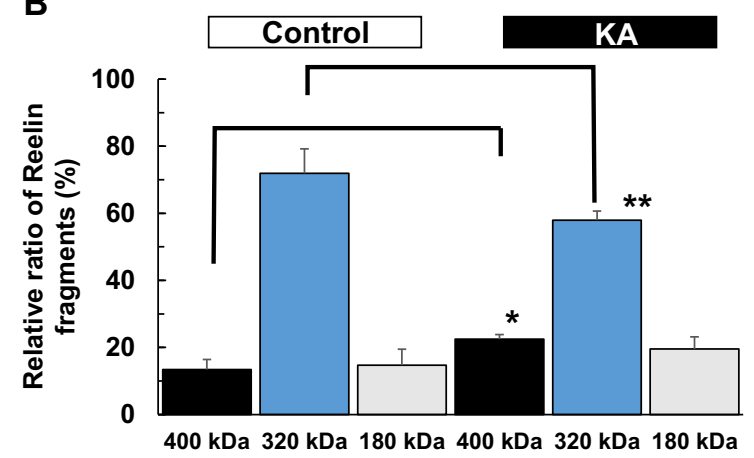

D

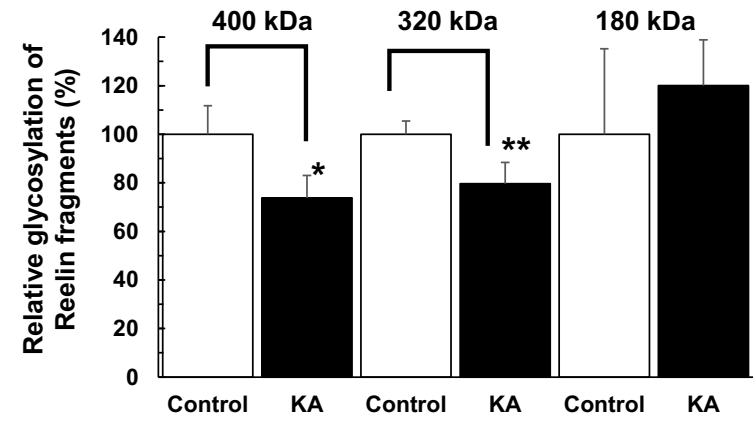


neurotransmission at the postsynaptic membrane, enhances inhibitory neurotransmission by allosterically modulating $\mathrm{GABA}_{\mathrm{A}}$ receptor-mediated $\mathrm{Cl}^{-}$current, and reduces spontaneous motor seizures in rats with KA-induced epilepsy [21]. A recent study reported that $\mathrm{KA}$ administration into the rat brain, resembling a chronic model of epilepsy in vivo, altered the proteolytic processing of Reelin [18]. Within short durations, following administration of KA reduced both cell viability and the mitochondrial activity in a dose-dependent manner (Fig. 1), and TPM significantly reduced KA-induced neural toxicity (Fig. 2), indicating that this paradigm closely mimicked in vitro early stage epilepsy. Our acute KAinduced epilepsy model in neuronal cells allowed detection of Golgi complex fragmentation/dispersal (Figs. 3-6) and the collapse of ER-lysosome-Golgi network (Figs. 4 and 5). In consideration of this previous study [18] indicating Reelin as closely associated with cell death in a chronic model of epilepsy, the present data now implicate that Reelin also may play a critical role in the early stages of epilepsy, as a result of Golgi complex fragmentation. Additional in vivo experiments are warranted to further elucidate the molecular mechanisms accompanying this Reelin-Golgi complex fragmentation in epilepsy models.

Despite being linked to a significant number of neurodegenerative diseases, the role of Golgi complex fragmentation in mediating neurodegeneration remains relatively underexplored [23, 24]. The initiation of Golgi complex fragmentation in Alzheimer's disease has been reported to involve Cdk5 phosphorylating the $\mathrm{pH}$-sensitive cis-Golgi protein GM130, and subsequently, GM130 is digested in lysosome [7]. Degradation of GM130 is associated with decreasing intracellular $\mathrm{pH}$, and its depletion interferes with ER-lysosomeGolgi vascular trafficking [36]. We observed decreased expression of GM130 in the acute stage of KA-induced neurotoxicity in comparison with healthy control groups (Fig. 9). Here, we found that epileptic activity was induced in vitro via KA-mediated activation of glutamatergic kainate receptors that respond to the neurotransmitter glutamate, coupled with Golgi complex fragmentation (Figs. 3-6). Glutamate deactivation occurs predominantly by glutamate transporter (EAA) in synapse and by glutamine synthase which catalyzes glutamate neutralization in adjacent glial cells. Excessive glutamate influx overloads the neutralizing capacity of EAA and hampers glutamate-glutamine recycling activity, leading to decreases in the intracellular $\mathrm{pH}$ in neurons. With these observations in mind, excessive activation of glutamate receptors on neurons may cause extreme decrements in intracellular $\mathrm{pH}$, which appears to trigger the initiation of Golgi complex fragmentation and spread of seizure area in an epileptic brain. An alternative possibility is that ROS/lipid peroxides or unexpected secondary products directly attack the Golgi complex membranes leading to disruption of Golgi's ultra-ribbon structure and its fragmentation.
Protein glycosylation is an important posttranslational process that occurs at the ER-lysosome-Golgi network. Glycosylation serves to stabilize the three-dimensional structure of the protein, allowing for selective protein interactions that permit multiple distinct signal transduction patterns from the same gene. Furthermore, glycosylation aids in protein folding, affording intermediates more hydrophilic, which prevents protein aggregation, a crucial cascade event for neurodegeneration. Indeed, many pathologic proteins associated with neurodegenerative diseases (e.g., amyloid precursor protein, $\beta$ secretase 1 , tau, $\alpha$-synuclein, and superoxide dismutase) are glycosylated [37]. Although the molecular mechanisms underlying protein glycosylation disorders are quite complex, it has been reported that interruption of the ER-lysosome-Golgi network contributes to the progression of neurodegenerative diseases. Processing glycosylation of Reelin is tightly regulated in ER/Golgi apparatus. Reelin expression and glycosylation patterns are altered in the frontal cortex and cerebellum of Alzheimer's disease patients [11]. The 180-kDa Reelin fragment interacts with $\alpha 3 \beta 1$ integrin receptors [38] but does not interact with ApoER2 and VLDL receptors [39]. In the present study, protein expression and glycosylation levels of 180$\mathrm{kDa}$ Reelin fragments were comparable between control (healthy neurons) and PRNCs treated with $5 \mu \mathrm{M}$ KA for 3 days (albeit early stage epilepsy) (Fig. 8). Expression and glycosylation of 320-kDa Reelin fragment were significantly increased in control compared with the KA-treated group, suggesting that Golgi complex fragmentation and collapse of the ER-lysosome-Golgi network likely caused the decreased Reelin processing which might have contributed to initiation and progression of epilepsy. Administration of Reelin into the hippocampus has been shown to enhance LTP as result of the activation of SFKs, which increase $N$-methyl-D-aspartate (NMDA) receptor activity [16]. These observations advance the notion that $320-\mathrm{kDa}$ Reelin fragment protein is a major neuromodulator that (1) increases glutamatergic neurotransmission mediated by the postsynaptic ApoER2 and VLDL receptors and therefore enhances synaptic plasticity, and (2) prevents the suppression of NMDA receptor and LTP in epilepsy patient's brains and altered expression of Reelin (fragments ratio) and its signal transduction (glycosylation patterns), in part, participate in the initiation of epilepsy.

The present results revealed that Golgi complex fragmentation in initiation of KA neurotoxicity could decrease the physiological function of Reelin. Golgi complex fragmentation and Reelin dysfunction may be considered as disease biomarkers, as well as therapeutic targets for epilepsy. A limitation of the present study is the use of rat E18 primary cortical cultures, with all endpoint readouts performed after 3 days in vitro. Accordingly, at this stage, the neurons were immature and had not formed any functional synaptic contacts yet. In order to recognize whether the observed aberrations in Golgi and Reelin translate to altered functional 
synaptic connectivity of primary neurons will require the use of mature functionally interconnected neurons. Moreover, we recognized the need for confirming the expression and proper localization of glutamate receptors in primary neurons and complemented by in vivo data to strengthen the clinical relevance of the findings. Given that Reelin is expressed in GABAergic interneurons (representing a minor neuronal population in E18 cortical neurons), additional studies are also warranted to provide some mechanistic insights how KA-induced hyperexcitability in primary neurons alters proteolytic processing and glycosylation of Reelin in interneurons. That epilepsy is a network disease may limit the direct translational application of primary neurons, which represent an artificial system with a specific number of neuronal subtypes. Nonetheless, the present results provide valuable informative data for understanding disease pathology and developing treatments directed at targeting immature neurons expressing Golgi and Reelin dysregulation. In this study, we report that KA irreversibly damages the endoplasmic reticulum-lysosome-Golgi network which then leads to abnormal Reelin proteolytic processing. Restoring and reinforcing the ER-lysosome-Golgi network and its interaction with Reelin could be exploited as novel therapeutic regimens for attenuating epilepsy and relevant neurodegenerative diseases.

Acknowledgments This work was supported by USF OR\&I HSC18330 \& COM HSC-18300 (YK), NIH NINDS RO1 1R01NS07195601 (CVB), James and Esther King Biomedical Research Program 09 KB01-23123 (CVB) and 1KG01-33966 (CVB), and USF Department of Neurosurgery and Brain Repair Funds (CVB). Part of this manuscript was presented as an abstract, "Golgi complex fragmentation/dispersal initiates neuronal aggravation in epilepsy: Reelin poses as a potential therapeutic target" at the American Society for Neural Therapy and Repair 21st Annual Conference, April 24-26, 2014, Clearwater, Florida.

Conflict of Interest The authors declare no competing interests.

Compliance with Ethical Standards The authors declare adherence to the journal's policies for upholding the integrity of the scientific record, in particular observance of the guidelines set forth by the Committee on Publication Ethics (COPE), including but not limited to the authors refraining from misrepresenting research results which could damage the trust in the journal, the professionalism of scientific authorship, and ultimately the entire scientific endeavor. Along the lines of maintaining integrity of the research and its presentation, the authors follow the rules of good scientific practice, which include the following: (1) The manuscript has not been submitted to more than one journal for simultaneous consideration (2) the manuscript has not been published previously (partly or in full), except in an abstract form, (3) a single study is not split up into several parts to increase the quantity of submissions and submitted to various journals or to one journal over time, (4) no data have been fabricated or manipulated (including images) to support your conclusions, (5) no data, text, or theories by others are presented as if they were the author's own ("plagiarism"), and (6) proper acknowledgements to other works have been given. The authors whose names appear on the submission have contributed sufficiently to the scientific work and therefore share collective responsibility and accountability for the results. Upon request, the authors are prepared to send relevant documentation or data in order to verify the validity of the results. This could be in the form of raw data, samples, records, etc.To ensure objectivity and transparency in research and to ensure that accepted principles of ethical and professional conduct have been followed, the authors have included information regarding sources of funding and potential conflicts of interest (financial or non-financial). This work was supported by USF OR\&I HSC-18330 \& COM HSC-18300 (YK), NIH NINDS RO1 1R01NS071956-01 (CVB), James and Esther King Biomedical Research Program 09 KB-01-23123 (CVB) and 1KG01-33966 (CVB), and USF Department of Neurosurgery and Brain Repair Funds (CVB).

Open Access This article is distributed under the terms of the Creative Commons Attribution License which permits any use, distribution, and reproduction in any medium, provided the original author(s) and the source are credited.

\section{References}

1. Cendes F (2012) Epilepsy in 2011: insights into epilepsy treatments and biomarkers. Nat Rev Neurol 8(2):70-71. doi:10.1038/nrneurol. 2011.223

2. Yasuhara T, Agari T, Kameda M, Kondo A, Kuramoto S, Jing M, Sasaki T, Toyoshima A et al (2013) Regenerative medicine for epilepsy: from basic research to clinical application. Int J Mol Sci 14(12):23390-23401. doi:10.3390/ijms 141223390

3. Yadav S, Puri S, Linstedt AD (2009) A primary role for Golgi positioning in directed secretion, cell polarity, and wound healing. Mol Biol Cell 20(6):1728-1736. doi:10.1091/mbc.E08-10-1077

4. Thayer DA, Jan YN, Jan LY (2013) Increased neuronal activity fragments the Golgi complex. Proc Natl Acad Sci U S A 110(4):14821487. doi:10.1073/pnas.1220978110

5. Brandizzi F, Barlowe C (2013) Organization of the ER-Golgi interface for membrane traffic control. Nat Rev Mol Cell Biol 14(6):382 392. doi: $10.1038 / \mathrm{nrm} 3588$

6. Warren G (1993) Membrane partitioning during cell division. Annu Rev Biochem 62:323-348. doi:10.1146/annurev.bi.62.070193. 001543

7. Sun KH, de Pablo Y, Vincent F, Johnson EO, Chavers AK, Shah K (2008) Novel genetic tools reveal Cdk5's major role in Golgi fragmentation in Alzheimer's disease. Mol Biol Cell 19(7):3052-3069. doi:10.1091/mbc.E07-11-1106

8. Cooper AA, Gitler AD, Cashikar A, Haynes CM, Hill KJ, Bhullar B, Liu K, Xu K et al (2006) Alpha-synuclein blocks ER-Golgi traffic and Rab1 rescues neuron loss in Parkinson's models. Science 313(5785):324-328. doi:10.1126/science.1129462

9. Stieber A, Chen Y, Wei S, Mourelatos Z, Gonatas J, Okamoto K, Gonatas NK (1998) The fragmented neuronal Golgi apparatus in amyotrophic lateral sclerosis includes the trans-Golgi-network: functional implications. Acta Neuropathol 95(3):245-253

10. Sakurai A, Okamoto K, Fujita Y, Nakazato Y, Wakabayashi K, Takahashi H, Gonatas NK (2000) Fragmentation of the Golgi apparatus of the ballooned neurons in patients with corticobasal degeneration and Creutzfeldt-Jakob disease. Acta Neuropathol 100(3):270 274

11. Botella-Lopez A, Burgaya F, Gavin R, Garcia-Ayllon MS, GomezTortosa E, Pena-Casanova J, Urena JM, Del Rio JA et al (2006) Reelin expression and glycosylation patterns are altered in Alzheimer's disease. Proc Natl Acad Sci U S A 103(14):55735578. doi:10.1073/pnas.0601279103

12. Hellwig S, Hack I, Kowalski J, Brunne B, Jarowyj J, Unger A, Bock $\mathrm{HH}$, Junghans D et al (2011) Role for Reelin in neurotransmitter release. J Neurosci 31(7):2352-2360. doi:10.1523/JNEUROSCI. 3984-10.2011 
13. Lacor PN, Grayson DR, Auta J, Sugaya I, Costa E, Guidotti A (2000) Reelin secretion from glutamatergic neurons in culture is independent from neurotransmitter regulation. Proc Natl Acad Sci U S A 97(7): 3556-3561. doi:10.1073/pnas.050589597

14. D'Arcangelo G, Homayouni R, Keshvara L, Rice DS, Sheldon M, Curran T (1999) Reelin is a ligand for lipoprotein receptors. Neuron 24(2):471-479

15. Senturk A, Pfennig S, Weiss A, Burk K, Acker-Palmer A (2011) Ephrin Bs are essential components of the Reelin pathway to regulate neuronal migration. Nature 472(7343):356-360. doi:10.1038/ nature 09874

16. Knuesel I (2010) Reelin-mediated signaling in neuropsychiatric and neurodegenerative diseases. Prog Neurobiol 91(4):257-274. doi:10. 1016/j.pneurobio.2010.04.002

17. Haas CA, Dudeck O, Kirsch M, Huszka C, Kann G, Pollak S, Zentner J, Frotscher M (2002) Role for reelin in the development of granule cell dispersion in temporal lobe epilepsy. J Neurosci 22(14)):5797-5802

18. Tinnes S, Ringwald J, Haas CA (2013) TIMP-1 inhibits the proteolytic processing of Reelin in experimental epilepsy. FASEB J 27(7): 2542-2552. doi:10.1096/fj.12-224899

19. Lussier AL, Lebedeva K, Fenton EY, Guskjolen A, Caruncho HJ, Kalynchuk LE (2013) The progressive development of depressionlike behavior in corticosterone-treated rats is paralleled by slowed granule cell maturation and decreased reelin expression in the adult dentate gyrus. Neuropharmacology 71:174-183. doi:10.1016/j. neuropharm.2013.04.012

20. Krstic D, Pfister S, Notter T, Knuesel I (2013) Decisive role of Reelin signaling during early stages of Alzheimer's disease. Neuroscience 246:108-116. doi:10.1016/j.neuroscience.2013.04.042

21. Grabenstatter HL, Dudek FE (2008) A new potential AED, carisbamate, substantially reduces spontaneous motor seizures in rats with kainate-induced epilepsy. Epilepsia 49(10):1787-1794. doi:10. 1111/j.1528-1167.2008.01657.x

22. Bialer M, White HS (2010) Key factors in the discovery and development of new antiepileptic drugs. Nat Rev Drug Discov 9(1):68-82. doi:10.1038/nrd2997

23. Nakagomi S, Barsoum MJ, Bossy-Wetzel E, Sutterlin C, Malhotra V, Lipton SA (2008) A Golgi fragmentation pathway in neurodegeneration. Neurobiol Dis 29(2):221-231. doi:10.1016/j.nbd.2007.08.015

24. Chang CF, Huang HJ, Lee HC, Hung KC, Wu RT, Lin AM (2012) Melatonin attenuates kainic acid-induced neurotoxicity in mouse hippocampus via inhibition of autophagy and alpha-synuclein aggregation. J Pineal Res 52(3):312-321. doi:10.1111/j.1600-079X.2011. 00945.X

25. Kaneko Y, Tajiri N, Shojo H, Borlongan CV (2014) Oxygen-glucosedeprived rat primary neural cells exhibit DJ-1 translocation into healthy mitochondria: a potent stroke therapeutic target. CNS Neurosci Ther 20(3):275-281. doi:10.1111/cns.12208

26. Bell E, Cao X, Moibi JA, Greene SR, Young R, Trucco M, Gao Z, Matschinsky FM et al (2003) Rapamycin has a deleterious effect on MIN-6 cells and rat and human islets. Diabetes 52(11):2731-2739

27. Laemmli UK (1970) Cleavage of structural proteins during the assembly of the head of bacteriophage T4. Nature 227(5259):680-685
28. Neubig RR, Spedding M, Kenakin T, Christopoulos A, International Union of Pharmacology Committee on Receptor N, Drug C, International Union of Pharmacology Committee on Receptor Nomenclature and Drug Classification XXXVIII (2003) Update on terms and symbols in quantitative pharmacology. Pharmacol Rev 55(4):597-606. doi:10.1124/pr.55.4.4

29. Gibbs JW 3rd, Sombati S, DeLorenzo RJ, Coulter DA (2000) Cellular actions of topiramate: blockade of kainate-evoked inward currents in cultured hippocampal neurons. Epilepsia 41(Suppl 1): S10-S16

30. Burman JL, Bourbonniere L, Philie J, Stroh T, Dejgaard SY, Presley JF, McPherson PS (2008) Scyl1, mutated in a recessive form of spinocerebellar neurodegeneration, regulates COPI-mediated retrograde traffic. J Biol Chem 283(33):22774-22786. doi:10.1074/jbc. M801869200

31. Krstic D, Rodriguez M, Knuesel I (2012) Regulated proteolytic processing of Reelin through interplay of tissue plasminogen activator (tPA), ADAMTS-4, ADAMTS-5, and their modulators. PLoS One 7(10):e47793. doi:10.1371/journal.pone.0047793

32. Tinnes S, Schafer MK, Flubacher A, Munzner G, Frotscher M, Haas CA (2011) Epileptiform activity interferes with proteolytic processing of Reelin required for dentate granule cell positioning. FASEB J 25(3):1002-1013. doi:10.1096/fj.10-168294

33. Morita I, Kakuda S, Takeuchi Y, Itoh S, Kawasaki N, Kizuka Y, Kawasaki T, Oka S (2009) HNK-1 glyco-epitope regulates the stability of the glutamate receptor subunit GluR2 on the neuronal cell surface. J Biol Chem 284(44):30209-30217. doi:10.1074/jbc.M109. 024208

34. Yu FH, Mantegazza M, Westenbroek RE, Robbins CA, Kalume F, Burton KA, Spain WJ, McKnight GS et al (2006) Reduced sodium current in GABAergic interneurons in a mouse model of severe myoclonic epilepsy in infancy. Nat Neurosci 9(9):1142-1149. doi:10. 1038/nn1754

35. Baba T, Kameda M, Yasuhara T, Morimoto T, Kondo A, Shingo T, Tajiri N, Wang F et al (2009) Electrical stimulation of the cerebral cortex exerts antiapoptotic, angiogenic, and anti-inflammatory effects in ischemic stroke rats through phosphoinositide 3-kinase/Akt signaling pathway. Stroke 40(11):e598-e605. doi:10.1161/STROKEAHA. 109.563627

36. Mukhopadhyay S, Bachert C, Smith DR, Linstedt AD (2010) Manganese-induced trafficking and turnover of the cis-Golgi glycoprotein GPP130. Mol Biol Cell 21(7):1282-1292. doi:10.1091/mbc. E09-11-0985

37. Schedin-Weiss S, Winblad B, Tjernberg LO (2014) The role of protein glycosylation in Alzheimer disease. FEBS J 281(1):46-62. doi: 10.1111/febs. 12590

38. Dulabon L, Olson EC, Taglienti MG, Eisenhuth S, McGrath B, Walsh CA, Kreidberg JA, Anton ES (2000) Reelin binds alpha3beta1 integrin and inhibits neuronal migration. Neuron 27(1):33-44

39. Jossin Y, Gui L, Goffinet AM (2007) Processing of Reelin by embryonic neurons is important for function in tissue but not in dissociated cultured neurons. J Neurosci 27(16):4243-4252. doi:10.1523/ JNEUROSCI. 0023-07.2007 